\title{
Formation of Nonspecific Precipitants in Sera by Counterimmunoelectrophoresis
}

\author{
JOHN K. CHAN ${ }^{1 *}$ AND JAMES D. FOLDS ${ }^{1,2}$ \\ Department of Hospital Laboratories, North Carolina Memorial Hospital, ${ }^{1}$ and Department of Bacteriology \\ and Immunology, University of North Carolina, ${ }^{2}$ Chapel Hill, North Carolina 27514
}

Received 2 September 1980/Accepted 30 January 1981

\begin{abstract}
Formation of nonspecific precipitants in sera in different kinds of agarose and batches of barbital buffer by routine counterimmunoelectrophoresis was observed. These nonspecific precipitants consistently locating at the cathodal side of the well upon counterimmunoelectrophoresis can lead to the incorrect interpretation that a specific antibody is present in the patient's serum against the antigens tested. This observation indicates the importance of including a negative control (patient's serum alone) with each individual sample tested by counterimmunoelectrophoresis for the detection of specific antibody to reduce false-positives.
\end{abstract}

Patients with staphylococcal endocarditis and bacteremia frequently respond with high titers of antiteichoic acid antibody (ATA). The detection of ATA in patients can serve, in many cases, as an important adjunct to cultures for the diagnosis of staphylococcal infection. High titers of ATA can be especially useful when cultures are difficult to obtain or when the interpretation of culture is complicated by previous antibiotic therapy $(1,2,6)$. Currently, many methods, including gel diffusion, counterimmunoelectrophoresis (CIE), enzyme-linked immunosorbent assay, and radioimmunoassay, have been used for the detection of ATA $(4,5,7)$. CIE, a rapid procedure, has been widely used in many laboratories to detect bacterial antigens. In our laboratories, when CIE is used to detect the presence of bacterial antigens in patients' serum, the formation of an additional precipitant on the cathodal side of the patient's serum well is sometimes seen. This additional precipitant, formed outside of the area between the cathodal and anodal wells, did not seem to be a specific antigen-antibody precipitant because it was sometimes seen in sera which were free of any bacterial antigens. This led us to examine the frequency and consistency of the formation of nonspecific precipitants in some sera upon routine CIE.

\section{MATERIALS AND METHODS}

Media and buffers. Different kinds of agarose obtained from the following companies were used: BBL Microbiology Systems, Cockeysville, Md. (lot 501600); Difco Laboratories, Detroit, Mich. (Noble, lot 616470); Marine Colloids, Rockland, Maine (Seakem, lot 60136); and GIBCO Laboratories, Grand Island,
N.Y. (lot A452365).

Barbital buffers were made up with calcium lactate pentahydrate (Fisher Scientific Co., Fair Lawn, N.J., lot 780899), barbital sodium (Fisher Scientific Co., lot 783514 or 774675), and barbitals (Fisher Scientific Co., lot 740822 or Sigma Chemical Co., St. Louis, Mo., lot 108C-0506). Continuous CIE was employed, in which gels at a concentration of $0.75 \%$ were prepared in 0.05 $\mathrm{M}$ barbital buffer at pH 8.6 , and the same buffer was used in the electrophoresis chamber reservoirs.

Samples. Sera were obtained from normal human blood donors; urine and cerebrospinal fluid were obtained from routine samples coming into the laboratory.

CIE procedure. The method of CIE was similar to that of Leffell et al. (3). CIE was performed in an electrophoresis unit (MRA Corp., Boston, Mass.) at room temperature, and current was supplied by a Beckman Duostate (Beckman Instruments, Inc., Fullerton, Calif.) which could deliver either constant voltage or constant current. Plastic plates (15 by $100 \mathrm{~mm}$; Lab-Tek Products, Div. Miles Laboratories Inc., Naperville, Ill.) coated with $15 \mathrm{ml}$ of agarose were used. Paired wells $2 \mathrm{~mm}$ in diameter were cut $3 \mathrm{~mm}$ apart. The procedure used to test sera for the formation of nonspecific precipitants was similar to the routine procedure used to detect the presence of ATA. Sera to be tested were placed in the anodal wells and subjected to $15 \mathrm{~min}$ of electrophoresis before the addition of either distilled water or barbital buffer to the cathodal well. The plates were run at $150 \mathrm{~V}$ constant voltage for a total of $35 \mathrm{~min}$. The electric circuit was completed with wicks made up of Whatman no. 3 filter paper (Whatman, Clifton, N.J.). After electrophoresis, the plates were flooded with cold normal saline and precipitant formation was observed under indirect light immediately and after overnight incubation. Final readings were made from the overnight incubation at $4^{\circ} \mathrm{C}$. 


\section{RESULTS}

Nonspecific precipitants formed in normal serum alone upon CIE were seen with all of the different kinds of agarose and batches of barbital buffer used in this study (Table 1). However, when 40 samples of cerebrospinal fluid or urine were run in the same routine, $98 \%$ of the samples failed to show any kind of nonspecific precipitant with any of the agarose and buffer systems used.

\section{DISCUSSION}

The detection of ATA in patients' serum by CIE can be used as an important adjunct to cultures in the diagnosis of some forms of staphylococcal infection. In our CIE system, the locating of nonspecific precipitants at the cathodal side of the well was observed with some sera alone (Fig. 1). The consistent locating of this nonspecific precipitant band at the cathodal side of the well with some sera may not interfere with the interpretation, if the presence of bacterial antigens is studied. This is because the patient's serum would be put at the cathodal well, and the nonspecific precipitant line, if present, will form outside the area in which a specific antigen-antibody precipitant would normally be expected. However, if one is testing for the presence of a specific antibody (e.g., ATA or candida antibody) in the serum, caution should be exercised in the search for the specific antigen-antibody precipitant because the patient's serum would be located at the anodal well. The nonspecific precipitant formed around the area in which the specific antigen-antibody precipitant is normally observed may obscure the interpretation. The reason for the high percentage of

TABLE 1. Effect of different batches of barbital buffer and supporting agarose on nonspecific precipitant formation in normal sera by CIE

\begin{tabular}{ccr}
\hline Batch & $\begin{array}{c}\text { No. of } \\
\text { specimens } \\
\text { tested }\end{array}$ & $\begin{array}{c}\text { No. (\%) of } \\
\text { specimens with } \\
\text { nonspecific } \\
\text { precipitants }\end{array}$ \\
\hline $1^{a}$ Noble & 352 & $258(73)$ \\
GIBCO & 374 & $269(72)$ \\
Seakem & 339 & $96(28)$ \\
$2^{b}$ & & \\
Noble & 308 & $255(83)$ \\
GIBCO & 308 & $213(69)$ \\
Seakem & 308 & $78(25)$ \\
BBL & 308 & $175(67)$ \\
\hline
\end{tabular}

\footnotetext{
${ }^{a}$ Batch 1 was made with Fisher barbital sodium CIV lot 783514 and Fisher barbital C-IV lot 740832.

${ }^{b}$ Batch 2 was made with Fisher barbital sodium CIV lot 774675 and Sigma barbital lot 108C-0506.
}

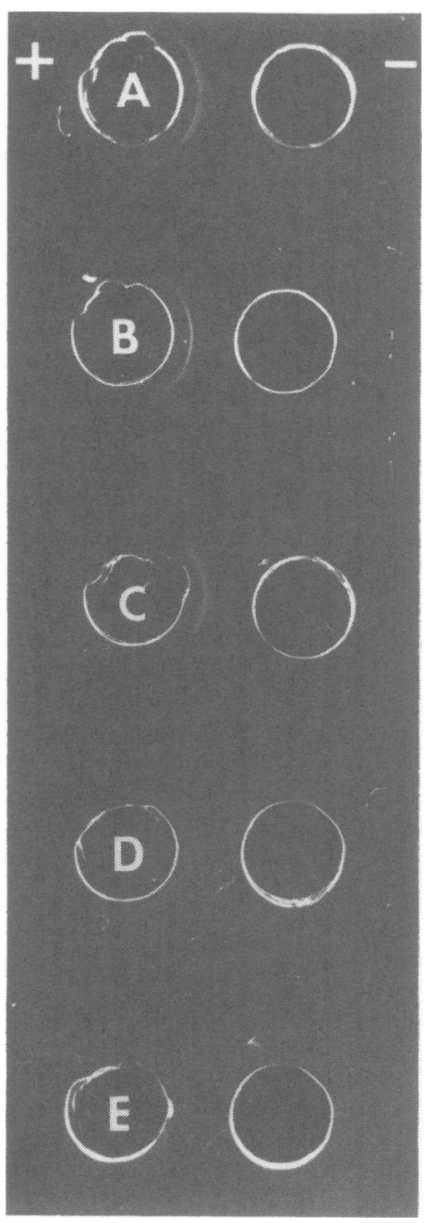

FIG. 1. Nonspecific precipitant formation with normal human sera $A, B$, and $C$, but not $D$ and $E$, upon the completion of $C I E$.

nonspecific precipitants observed in this system with sera but rarely with urine and CSF could be due to the presence of cryoglobulins or other precipitable proteins in some of the sera employed in this study. It may also be due to the possibility that, in some of the sera used in this study, there were pre-existing antibodies which recognize antigens present in the agars or buffers. This observation of nonspecific precipitants in certain sera in different agarose preparations and different buffers indicates the importance of running a negative control (patient's serum alone) to cover the possibility that the nonspecific precipitant may also form occasionally in other CIE procedures. This inclusion of a negative control will allow us to make a better judgement in cases where the nonspecific precipitant resembles the specific antigen-antibody precipitant. The benefit of inclusion of a nega- 
tive control can also apply to the detection of any specific antibody in patients' serum by CIE.

\section{LTERATURE CITED}

1. Crowder, J. G., and A. White. 1972. Teichoic acid antibodies in staphylococcal and nonstaphylococcal endocarditis. Ann. Intern. Med. 77:87-90.

2. Larinkari, U. M., M. V. Valtonen, M. Sravas, and V. V. Valtonen. 1977. Teichoic acid antibody test. Arch. Intern. Med. 137:1522-1525.

3. Leffell, M. S., J. D. Folds, and B. Wasilauskas. 1978. Counterimmunoelectrophoretic detection of a high incidence of precipitin reactions in normal human sera against staphylococcal teichoic acids and protein A. J. Clin. Microbiol. 8:591-597.
4. Mackowiak, P. A., and J. W. Smith. 1978. Teichoic acid antibodies in chronic staphylococcal osteomyelitis. Ann. Intern. Med. 89:494-496.

5. Nagel, J. G., C. U. Tuazon, T. A. Cardella, and J. N. Sheagren. 1975. Teichoic acid serologic diagnosis of staphylococcal endocarditis. Use of gel diffusion and counterimmunoelectrophoresis methods. Ann. Intern. Med. 82:13-17.

6. Tuazon, C. U., and J. N. Sheagren. 1976. Teichoic acid antibodies in the diagnosis of serious infections with Staphylococcus aureus. Ann. Intern. Med. 84:543-546.

7. Wheat, L. J., R. B. Kohler, and A. White. 1978. Solidphase radioimmunoassay for immunoglobulin A Staphylococcus aureus antibody in serious staphylococcal infection. Ann. Intern. Med. 89:467-472. 